\title{
CT-1 and Oct-2 DNA-binding site specificity is regulated in vitro by different kinases
}

\author{
Stephanie J. GRENFELL ${ }^{*} \dagger$, David S. LATCHMAN $\dagger$ and N. Shaun B. THOMAS* $\nleftarrow$ \\ *Department of Haematology, University College London Medical School, 98 Chenies Mews, London WC1E 6HX, U.K., and †Department of Molecular Pathology, \\ University College London Medical School, The Windeyer Building, 46 Cleveland Street, London, W1P 6DB, U.K.
}

\begin{abstract}
The transcription factors Oct-1 and Oct-2 bind differentially to three octamer binding sequences corresponding to the octamer binding site from the $\mathrm{H} 2 \mathrm{~B}$ promoter [ATGCTAATAA], a simple TAATGARAT motif, found in herpes simplex virus IE4/5 genes [GCGGTAATGAGAT], and a perfect consensus overlapping octamer/TAATGARAT motif [ATGCTAATGAGAT]. By comparing the effects of protein kinase $\mathrm{A}$, protein kinase $\mathrm{C}$ and casein kinase 2 in vitro on the binding of Oct- 1 and Oct- 2 to the three motifs, we show that the actions of these kinases regulate Oct-1 and Oct-2 DNA binding independently of each other in
\end{abstract}

a binding-site-specific manner. Inhibition of cellular phosphatases also regulate Oct-1 and Oct-2 DNA binding in a bindingsite-specific manner. Both kinase and phosphatase activity are important for regulating the DNA binding activity of Oct-1 and Oct-2 because, in the presence of phosphatase inhibitors, protein kinase A attenuates the binding of both Oct- 1 and Oct- 2 to the octamer binding site but enhances binding when phosphatase inhibitors are omitted. Thus the DNA specificity of Oct-1 and Oct- 2 can be regulated in vitro by the action of different kinases.

\section{INTRODUCTION}

The octamer sequence element (consensus 5'-ATGCAAATNA-3') is found in the promoters and enhancers of a number of cellular genes, including those encoding histone H2B small nuclear RNA, interleukin 2 (IL-2) and immunoglobulin (reviewed in [1]). A number of different cellular transcription factors that interact with this octamer binding sequence have been purified and cloned. These proteins are members of a family of transcription factors that contain a POU domain, consisting of an $\mathrm{N}$ terminal $\mathrm{POU}_{\mathrm{S}}$ sub-domain and a C-terminal $\mathrm{POU}_{\mathrm{HD}}$ homoeodomain that form a bipartite DNA-binding domain [2-5], and include both Oct-1 [2] and Oct-2 [3-7]. Oct-1 is expressed in virtually all cell types [8,9] and plays a critical role in the transcription of small nuclear RNA and H2B genes [10,11]. Oct2 is expressed in B lymphocytes [3-5], where it is required for LPS induced proliferation and maturation of B-cells [12,13]. Oct-2 is also expressed in neuronal cells $[6,7]$ and has been implicated as a regulator of herpes simplex virus (HSV) latency [14].

Gene expression can be modulated through post-translational modification of transcription factors. Phosphorylation/ dephosphorylation of transcription factors is a common mechanism that regulates the binding of these proteins to specific DNA sequences and the activation of gene transcription (reviewed in $[15,16]$ ). Phosphorylation of Oct-1 by protein kinase A (PKA) inhibits its DNA-binding activity [17], and the calcium/ calmodulin-activated phosphatase, calcineurin, has been shown to augment Oct-1-dependent transcription [18]. Oct-1 is also phosphorylated in a cell-cycle-dependent manner, and hyperphosphorylation of Oct-1 by $\mathrm{p} 34^{c d c 2}$ is thought to terminate DNA binding during mitosis [19]. Oct-2 also becomes competent to activate transcription by protein phosphorylation [20] but the kinases involved have yet to be determined. These results clearly imply that changes in the phosphorylation status of Oct-1/Oct2 modify their DNA binding and/or the ability of Oct-1/Oct-2 to modulate transcription.
In addition to general effects on the ability of a transcription factor to bind DNA or activate transcription, phosphorylation can also modulate DNA-binding specificity. Indeed, Wang and Prives [21] have shown that phosphorylation differentially affects the ability of p53 to bind to different DNA binding sites. Furthermore, phosphorylation of Pit-1 modifies its DNA-binding activity in a sequence-specific manner [22,23]. Nonphosphorylated Pit- 1 binds to the thyrotropin $\beta$-subunit (TSH$\beta$ ) gene with lower affinity than phosphorylated Pit-1 and is a weak activator of gene expression. Protein kinase A (PKA)mediated phosphorylation of Pit- 1 enhances binding to TSH- $\beta$ elements 3-8-fold, whereas phosphorylation reduces Pit-1 DNA binding to the high-affinity binding site from the prolactin promoter [22,23]. Oct-1 and Oct-2 bind differently to three octamer binding sequences in a cell-type-specific manner [24], and we considered it possible that such differential binding could be regulated by phosphorylation. In this study we have investigated the effect(s) of different kinases and phosphatase inhibitors on nuclear Oct-1 and Oct-2, and demonstrate that they are regulated independently in a DNA binding-site-specific manner. We show that the ability of Oct- 1 and Oct- 2 to bind DNA is regulated by the addition of specific kinases/phosphatase inhibitors to nuclear extracts and that these differential effects are dependent on the DNA binding site.

\section{MATERIALS AND METHODS \\ Oligonucleotides}

Double-stranded oligonucleotides were labelled by phosphorylation with $\left[\gamma_{-}{ }^{32} \mathrm{P}\right]$ ATP (Amersham) and T4 polynucleotide kinase (Promega). Oligonucleotide probes corresponding to the octamer consensus motif, found in the $\mathrm{H} 2 \mathrm{~B}$ gene [ATGCAAATAA], a simple TAATGARAT motif, found in HSV immediate early 4/5 genes [GCGGTAATGAGAT], and a

Abbreviations used: CK-II, casein kinase 2; HSV, herpes simplex virus; IL-2, interleukin 2; PKA, protein kinase A; PKC, protein kinase C; PP, protein phosphatase; TSH- $\beta$, thyrotropin $\beta$-subunit.

* To whom correspondence should be addressed. 
perfect consensus overlapping octamer/TAATGARAT motif [ATGCTAATGAGAT] [25] were used.

\section{Cellular fractionation}

Daudi cell nuclear extracts were prepared by the method of Schreiber et al. [26].

\section{DNA mobility shift assays}

For binding, $1 \mu \mathrm{l}$ of nuclear extract $(2.5 \mu \mathrm{g})$ was mixed with $20 \mathrm{mM}$ Hepes buffer, $\mathrm{pH} 7.9$, containing $50 \mathrm{mM} \mathrm{KCl}, 0.5 \mathrm{mM}$ dithiothreitol, $5 \mu \mathrm{g}$ of poly(dI-dC), $1 \mu \mathrm{g}$ of salmon sperm DNA, $0.5 \mathrm{mM}$ PMSF, $2 \mu \mathrm{g} / \mathrm{ml}$ aprotinin, $1 \mu \mathrm{g} / \mathrm{ml}$ pepstatin, $1 \mu \mathrm{g} / \mathrm{ml}$ leupeptin and $8 \%(\mathrm{w} / \mathrm{v})$ Ficoll. Kinases, cofactors and phosphatase inhibitors were added as follows: for PKA reactions, 15 units of cAMP-dependent PKA, $1 \mathrm{mM} \mathrm{CaCl}_{2}, 1 \mathrm{mM} \mathrm{MgCl} \mathrm{M}_{2}$, $1 \mathrm{mM}$ cAMP and $30 \mu \mathrm{M}$ ATP were also added; for protein kinase $\mathrm{C}(\mathrm{PKC})$ reactions, $1 \mu \mathrm{g} / \mathrm{ml} \mathrm{PKC}(\mathrm{UBI}), 1 \mathrm{mM} \mathrm{CaCl}{ }_{2}$, $1 \mathrm{mM} \mathrm{MgCl}, 60 \mu \mathrm{g} / \mathrm{ml}$ diolein, $310 \mu \mathrm{g} / \mathrm{ml}$ phosphatidylserine and $30 \mu \mathrm{M}$ ATP were added; for casein kinase 2 (CK-II) reactions, $1 \mu \mathrm{g}$ of CK-II (UBI, Lake Placid, NY, U.S.A.), $1 \mathrm{mM}$ $\mathrm{MgCl}_{2}$ and $30 \mu \mathrm{M}$ ATP were added. The phosphatase inhibitors were added, where indicated, to a final concentration of $1 \mathrm{nM}$ or $1 \mu \mathrm{M}$ okadaic acid (Boehringer Mannheim), $50 \mathrm{mM}$ sodium fluoride, $1 \mathrm{mM}$ sodium orthovanadate and $1 \mathrm{mM} \beta$-glycerophosphate. In all cases the final volume was $30 \mu 1$.

After incubating at $30{ }^{\circ} \mathrm{C}$ for $20 \mathrm{~min}, 250 \mathrm{pg}$ of labelled probe was added and the binding reaction was allowed to continue for a further $15 \mathrm{~min}$ at room temperature. The DNA-protein complexes were then resolved by electrophoresis $\left(3 \mathrm{~h}, 4{ }^{\circ} \mathrm{C}, 150 \mathrm{~V}\right)$ on a $4 \%(\mathrm{w} / \mathrm{v})$ polyacrylamide gel in $0.25 \times$ Tris/borate/EDTA (prerun $1 \mathrm{~h}, 4^{\circ} \mathrm{C}, 150 \mathrm{~V}$ ). Complexes were revealed by autoradiography of the dried gel or by using a Phosphorimager (Fuji Bas 1000). The specificity of the Oct-1 and Oct-2 signals was determined as described previously [27] by competition with an excess of the appropriate probe, with mutant octamer or nonspecific binding sites.

All reagents were purchased from Sigma Chemical Co. unless stated otherwise.

\section{RESULTS}

\section{Phosphatase inhibitors modify 0ct-1 and 0ct-2 DNA binding} ability in a binding-site-specific manner

Phosphorylation and dephosphorylation are known to alter the nuclear protein activities of numerous proteins. Both Oct-1 and Oct-2 are phosphorylated in vivo ([19,20] and results not shown). To determine whether phosphorylation/dephosphorylation events could alter the DNA binding activities of Oct-1 and Oct-2, nuclear extracts, which contain not only phosphorylated Oct-1 and Oct-2 but also endogenous kinases and phosphatases, were treated with a general, non-specific phosphatase inhibitor 'cocktail' of sodium fluoride, sodium orthovanadate and $\beta$-glycerophosphate. The treated extract was then mixed with ${ }^{32} \mathrm{P}$-labelled probe and the extent of binding determined by retardation of the probe on non-denaturing polyacrylamide gels. The binding sites used were those containing the consensus octamer-binding site from the $\mathrm{H} 2 \mathrm{~B}$ promoter, a simple TAATGARAT motif, found in HSV immediate early 4/5 genes, and an overlapping octamer/TAATGARAT motif found in the upstream region of HSV-1 IE1 genes that binds both Oct-1 and Oct-2 with high affinity (Table 1) [25]. Inhibition of nuclear extract phosphatase activity decreases Oct-1 and Oct-2 DNA binding to TAATGARAT and octamer motifs. However, bind-
Table 1 Consensus DNA sequence comparison of the cellular octamer motif [27] and the HSV TAATGARAT motif [14] with the three functional octamer oligonucleotides used in this study

\begin{tabular}{ll}
\hline Octamer consensus & ATGCAAATNA \\
HSVIE consensus & RYGNTAATGARAT \\
HSV & GCGGTAATGAGAT \\
Octamer & ATGCAAATAA \\
Overlapping & ATGCTAATGAGAT \\
\hline
\end{tabular}

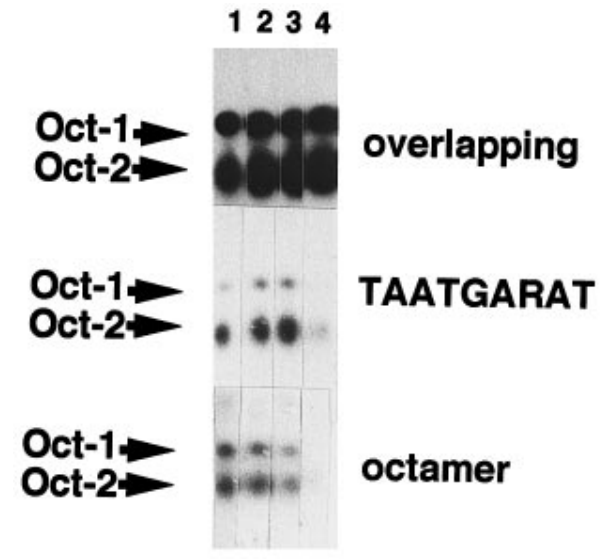

Figure 1 0ct-1 and 0ct-2 binding to three DNA motifs is affected by phosphatase inhibitors

DNA binding mobility assays were performed by using Daudi cell nuclear extract incubated in the presence or absence of okadaic acid or a general phosphatase inhibitor cocktail. Lane 1, nuclear extract; lane 2, nuclear extract plus $1 \mathrm{nM}$ okadaic acid; lane 3 , nuclear extract plus $1 \mu \mathrm{M}$ okadaic acid; lane 4, nuclear extract plus phosphatase inhibitor cocktail (see the Materials and methods section). The labelled oligonucleotides used correspond to the binding sites indicated.

ing of Oct-1 and Oct- 2 to the overlapping site was unaffected by inhibition of phosphatase activity. Results from one experiment are shown in Figure 1 and the results of three independent experiments are quantified in Table 2. In all cases Oct-1 and Oct2 were affected equally.

Having established that a general, non-specific phosphatase inhibitor cocktail modifies Oct-1 and Oct-2 DNA binding, we next examined whether okadaic acid, a specific inhibitor of phosphatase 1 (PP-1) and phosphatase 2A (PP-2A) [28], could also modify Oct-1 and Oct-2 DNA binding. We used okadaic acid at two concentrations that specifically inhibit PP-2A (1 nM), and both PP-1 and PP-2A $(1 \mu \mathrm{M})$. Consistent with our results using the phosphatase inhibitor cocktail, okadaic acid failed to modify Oct-1 or Oct-2 binding to the overlapping binding site (Figure 1, quantified in Table 2). Binding of Oct-1 and Oct-2 to the TAATGARAT binding site was also insensitive to okadaic acid treatment, implying that the inhibition of binding of Oct-1 and Oct-2 to the TAATGARAT motif by the phosphatase inhibitor cocktail is likely to be mediated by phosphatases other than PP-1 or PP-2A. In contrast, the inhibition of Oct-1 and Oct2 binding to the octamer motif is likely to be mediated by PP-2A, because $1 \mathrm{nM}$ okadaic acid inhibited binding to the same degree as the phosphatase inhibitor cocktail. Thus inhibition of phosphatase activity in the nuclear extract modifies Oct-1 and Oct-2 DNA binding activity in a sequence-specific manner. 
Table 2 Oct-1 and 0ct-2 binding to three DNA motifs are affected by phosphatase inhibitors

In each case, the amount of 0ct-1 and 0ct-2 DNA binding in the absence of kinases or cofactors has been set at $100 \%$, and other values are expressed relative to this value. Results are the means \pm S.E.M. for three experiments.

\begin{tabular}{lllll}
\hline \multirow{5}{*}{ Agent } & \multicolumn{3}{c}{ Binding site } \\
\cline { 3 - 5 } & & Overlapping & TAATGARAT & Octamer \\
\hline Control & & & \\
& & & 100 & 100 \\
Phosphatase inhibitor & Oct-2 & 100 & 100 & 100 \\
$\quad$ Cocktail & Oct-2 & $110.1 \pm 18.8$ & $71.5 \pm 9.2$ & $77.3 \pm 10.2$ \\
Okadaic acid $(1 \mathrm{nM})$ & Oct-1 & $116.2 \pm 10.4$ & $113.4 \pm 16.1$ & $69.3 \pm 15.2$ \\
& Oct-2 & $121.2 \pm 13.7$ & $108.9 \pm 11.9$ & $71.0 \pm 13.6$ \\
Okadaic acid $(1 \mu \mathrm{M})$ & Oct-1 & $122.2 \pm 13.9$ & $98.2 \pm 20.2$ & $63.2 \pm 16.9$ \\
& Oct-2 & $128.2 \pm 20.6$ & $100.0 \pm 17.1$ & $66.7 \pm 12.4$ \\
& & & & \\
\end{tabular}

Table 3 Oct-1 and Oct-2 binding to three DNA motifs are affected by different kinases

Details as for Table 2. The phosphatase inhibitor cocktail was added to each lysate. Results are the means \pm S.E.M. for three experiments

\begin{tabular}{llccc}
\hline \multicolumn{5}{c}{ Binding site } \\
\cline { 3 - 5 } Agent & & Overlapping & TAATGARAT & Octamer \\
\hline \multirow{2}{*}{ Control } & Oct-1 & 100 & 100 & 100 \\
& Oct-2 & 100 & 100 & 100 \\
PKA & Oct-1 & $117.0 \pm 2.6$ & $381.1 \pm 122.3$ & $62.2 \pm 11.5$ \\
& Oct-2 & $95.5 \pm 0.3$ & $178.5 \pm 59.2$ & $56.3 \pm 13.9$ \\
PKC & Oct-1 & $71.6 \pm 16.6$ & $57.4 \pm 29.6$ & $39.7 \pm 22.2$ \\
& Oct-2 & $113.9 \pm 15.4$ & $119.6 \pm 10.7$ & $113.9 \pm 30.7$ \\
CK-II & Oct-1 & $89.0 \pm 7.1$ & $86.6 \pm 8.7$ & $208.4 \pm 91.4$ \\
& Oct-2 & $97.4 \pm 12.7$ & $82.9 \pm 21.9$ & $217.8 \pm 93.1$ \\
& & & & \\
\hline
\end{tabular}

\section{PKA modifies 0ct-1 and Oct-2 DNA-binding activity in a sequence-specific manner}

PKA has been shown to phosphorylate two members of the POU homoeodomain transcription factor family, Oct-1 and Pit-1. Because PKA modifies the ability of Pit-1 DNA binding according to the DNA binding site used, we next examined the effects of PKA phosphorylation on the ability of both Oct-1 and Oct-2 to bind DNA specifically. PKA was added to the nuclear extract and phosphatase inhibitors were included in the reaction to ensure that we were investigating phosphorylation-mediated events. When nuclear extract was incubated with PKA, binding of Oct-1 to the octamer motif was reduced (Table 3). One such experiment is shown in Figure 2 (top panel). Such a finding is consistent with previously published reports [17], and we extend these observations to show that PKA also inhibits Oct-2 binding to the octamer motif. In this particular experiment the binding of Oct-2 is decreased more than Oct-1, but on average the effect of PKA is the same for both Oct-1 and Oct-2 (Table 3). We also investigated the effect of PKA on the ability of Oct-1 and Oct-2 to bind to the TAATGARAT and overlapping binding sites. In contrast with our observations regarding Oct-1 and Oct-2 and the octamer motif, PKA enhanced binding of both Oct-1 and Oct-2 to the TAATGARAT motif [Figure 2 (bottom panel) and Table 3]. Activation was not due to PKA binding to the motif, and was not observed in the presence of ATP and the cofactors alone (results not shown). As expected, because phosphatase inhibitors failed to modify octamer binding, PKA did not alter binding to the overlapping site.

As we have demonstrated that phosphatases also play a role in determining binding site specificity, we next examined the effect of PKA on the ability of Oct-1 and Oct-2 to bind to DNA in the presence or absence of phosphatase inhibitors. As shown in Figure 2 (top panel), when nuclear phosphatase activity is not inhibited, PKA enhances binding of both Oct-1 and Oct- 2 to the octamer binding site (compare lane 3,-PKA, with lane 4, + PKA). This implicates PKA-activated phosphatases in the regulation of Oct-1 and Oct-2 binding site specificity, and suggests that both kinase and phosphatase activity are important for regulating the DNA-binding activity of Oct-1 and Oct-2.

\section{Effect of CK-II and PKC on Oct-1 and Oct-2 binding to DNA}

To determine whether the effect observed with PKA was specific or could be produced by other serine/threonine kinases, we tested the ability of CK-II and PKC to modify Oct-1 and Oct-2 DNA binding. In contrast with our observations using PKA, adding PKC to nuclear extract had the same effect on binding to all three motifs. Further, we found that PKC modified Oct-1 DNA binding independently of Oct-2. Oct-1 binding activity was decreased, whereas Oct-2 binding activity was unaffected (Table 3 ). Therefore Oct- 1 and Oct- 2 can be regulated independently of each other.

In contrast with PKA and PKC, CK-II was effective in increasing the binding of both Oct-1 and Oct-2 to the octamer motif. However, CK-II failed to modify the binding of Oct-1 or Oct-2 to the TAATGARAT or overlapping motifs (Table 3). Thus other serine/threonine kinases also regulate Oct-1 and Oct2 binding activity in a binding-site-specific manner.

\section{DISCUSSION}

Oct-1 and Oct-2 exhibit cell-type-specific differential binding to three octamer binding sequences corresponding to the octamer binding site from the $\mathrm{H} 2 \mathrm{~B}$ promoter [ATGCTAATAA], a simple TAATGARAT motif, found in HSV IE4/5 genes [GCGGTAATGAGAT], and a perfect consensus overlapping octamer/ TAATGARAT motif [ATGCTAATGAGAT] [24]. The overlapping motif has been shown to bind a single molecule of either Oct- 1 or Oct- 2 with much higher affinity than either the octamer or TAATGARAT motif alone [25]. This observation may simply reflect the sequence specificity of the $\operatorname{POU}_{\mathrm{S}}$ [AATAT $(\mathrm{G} / \mathrm{T}) \mathrm{CA}$ ] and $\mathrm{POU}_{\mathrm{HD}}$ [RTAATNA] respectively [30]. Phosphorylation has been shown to modulate differentially the Pit-1 DNA binding to high- and low-affinity binding sites [22,23]. Previous studies have shown that Oct-1 is phosphorylated in a cell-cycle-dependent manner, and its hyperphosphorylation by $\mathrm{p} 34^{\mathrm{cdc} 2}$ terminates its DNA-binding activity during mitosis [19]. Similarly, PKA phosphorylation of Oct-1 inhibits its DNA-binding activity [17]. We have investigated the possibility that the cell-specific differential binding of Oct- 1 and Oct-2 to three octamer-binding sequences [24] could be regulated by different protein kinases. The experiments described in this study were performed by the addition of specific kinases or phosphatase inhibitors to nuclear extracts, which contain not only Oct- 1 and Oct-2, but also endogenous kinases and phosphatases. We chose specifically to carry out the experiments with nuclear extracts rather than using recombinant Oct- 1 and Oct- 2 because the nuclear Oct- 1 and Oct2 in whole cells are already phosphorylated whereas recombinant 


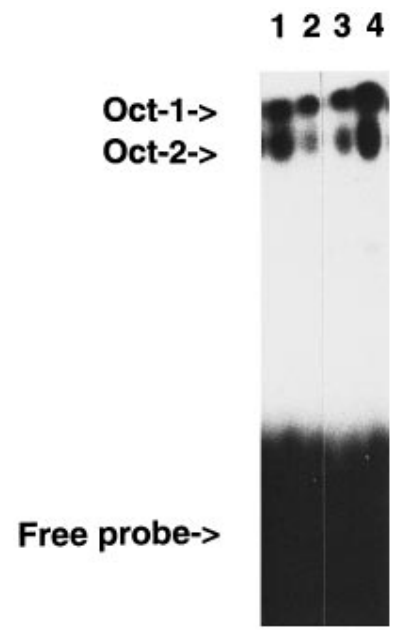

1234

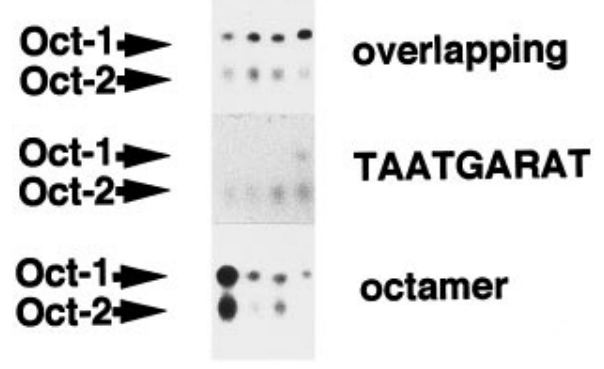

Figure 2 Effect of PKA on 0ct-1 and Oct-2 DNA binding

(Top panel) The effect of PKA on 0ct-1 and Oct-2 binding to the octamer motif is phosphatasedependent. Daudi cell nuclear extract was incubated with PKA in the presence or absence of phosphatase inhibitors (see the Materials and methods section). Each reaction mixture was subsequently assayed for DNA binding ability by using the octamer binding site. Lane 1 , nuclear extract plus $30 \mu \mathrm{M}$ ATP, $1 \mathrm{mM} \mathrm{MgCl}, 1 \mathrm{mM}$ cAMP and phosphatase inhibitor cocktail; lane 2, nuclear extract plus 15 units of PKA, $30 \mu \mathrm{M}$ ATP, $1 \mathrm{mM} \mathrm{MgCl}, 1 \mathrm{mM}$ cAMP and phosphatase inhibitor cocktail; lane 3 , nuclear extract plus $30 \mu \mathrm{M}$ ATP, $1 \mathrm{mM} \mathrm{MgCl}$ and $1 \mathrm{mM}$ CAMP; lane 4, nuclear extract plus 15 units of PKA, $30 \mu \mathrm{M} \mathrm{ATP}, 1 \mathrm{mM} \mathrm{MgCl}$, and $1 \mathrm{mM}$ cAMP. (Bottom panel) Oct-1 and Oct-2 binding to three DNA motifs are modified by PKA in a binding site-specific manner. Daudi cell nuclear extract was incubated in the presence and absence of PKA, $1 \mathrm{mM}$ cAMP, $30 \mu \mathrm{M}$ ATP for $20 \mathrm{~min}$ at $30^{\circ} \mathrm{C}$. Each reaction mixture was subsequently assayed for DNA-binding ability by using the octamer. TAATGARAT and overlapping binding sites, as indicated. Lane 1, nuclear extract; lane 2, nuclear extract plus $30 \mu \mathrm{M}$ ATP and $1 \mathrm{mM} \mathrm{MgCl}$; lane 3, nuclear extract plus $30 \mu \mathrm{M} \mathrm{ATP,} 1 \mathrm{mM} \mathrm{MgCl}$ and $1 \mathrm{mM}$ cAMP; lane 4, nuclear extract plus 15 units of PKA, $30 \mu \mathrm{M} \mathrm{ATP}, 1 \mathrm{mM} \mathrm{MgCl}{ }_{2}$ and $1 \mathrm{mM}$ CAMP

Oct-1/-2 produced in bacteria are not. Therefore our experiments determine the effects of different kinases on the ability of cellular Oct- 1 and Oct- 2 to bind to the octamer, TAATGARAT and overlapping DNA binding sites.

Our results demonstrate that PKA-mediated phosphorylation modifies both Oct-1 and Oct-2 DNA binding in a sequencespecific manner. Consistent with previously published results [17], we have demonstrated that after PKA-mediated phosphorylation, Oct-1 binding to the octamer binding site from the $\mathrm{H} 2 \mathrm{~B}$ promoter is inhibited. Our studies extend these observations and show that Oct-2 binding to the octamer motif is similarly inhibited by the addition of PKA to the nuclear extract. PKA phosphorylates both Oct-1 and Pit-1 in vitro at the PKA consensus recognition sequence, ZZXT/SI (where $\mathrm{Z}$ is any basic amino acid, $\mathrm{T}$ is $\mathrm{Thr}^{384}, \mathrm{~S}$ is $\mathrm{Ser}^{385}$, I any apolar amino acid and $\mathrm{X}$ any amino acid), located in the $\mathrm{POU}_{\mathrm{HD}}[17,22]$. This sequence is conserved throughout the family of POU domain transcription factors. Because PKA has the same effect on both Oct-1 and Oct2 DNA binding, it is likely that ZZXT/SI in the POU domain of Oct-2 is also phosphorylated by PKA. Determination of the crystal structure of the POU-specific DNA-binding domain of Oct-1 has revealed that $\mathrm{Thr}^{384}$ is in direct contact with DNA [31,32]. PKA-mediated phosphorylation of $\mathrm{Thr}^{384}$ could therefore interfere with DNA binding by electrostatic repulsion between the phosphate groups on the protein and the phosphate groups on the DNA [15].

Interestingly, PKA failed to inhibit Oct-1 and Oct-2 binding to binding sites corresponding to a simple TAATGARAT motif and the overlapping octamer/TAATGARAT motif. Indeed, Oct-1 and Oct-2 DNA binding to the TAATGARAT site was enhanced, whereas binding to the overlapping motif was unaffected. This demonstrates that Oct- 1 and Oct- 2 binding can be modified by PKA in a binding-site-specific manner. Such an observation is not restricted to PKA, because CK-II enhances Oct-1 and Oct-2 DNA binding to the octamer motif, but not to the TAATGAGAT or overlapping binding sites. It has been shown that both Oct-1 [19] and Oct-2 are phosphorylated in a cell-cycle-dependent manner, and that CK-II-mediated phosphorylation of transcription factors regulates cellular proliferation (reviewed in [33]). Thus differential regulation of DNA binding could represent a mechanism whereby some genes that have octamer binding sites are expressed in a cell-cycle-dependent manner, and others are expressed constitutively.

Examination of the amino acid sequences for Oct-1 and Oct2 reveals multiple PKC consensus recognition sites. In our study, PKC modified the binding of Oct-1 independently of that of Oct-2, suggesting that any direct phosphorylation probably occurs on a non-conserved phosphorylation site. If so, the site of phosphorylation would be in a region other than the highly conserved POU domain, and inhibition of DNA binding would most probably be induced by changing the conformation of the molecule [15]. Alternatively, PKC might modify Oct-1 DNA binding indirectly, for example by phosphorylating an accessory protein in the nuclear extract. However, these results exemplify one mechanism whereby proteins that display the same binding site specificity can differentially regulate transcription. Indeed, previous studies have demonstrated that the selective association of accessory proteins such as the HSV-1 transactivator protein, VP16 [34,35], can also modify Oct-1 DNA binding and transcription independently of Oct-2. Together with the observation that Oct-1 cannot adequately compensate for Oct-2 deficiency in mature B cells $[12,13]$ these results imply independent functions for B cell Oct-1 and Oct-2. The physiological role of PKC activation on Oct-1 has been studied by the addition of phorbol ester to T-cells [36-40] and to epithelial cells [41]. However, the effect of PKC activation on Oct-1 is controversial as the addition of phorbol ester to T-cells has been reported not to induce Oct-1 DNA binding in certain circumstances [36-39] but does so in others [40]. It is interesting to note that phorbol ester induces octamer-dependent transcription of an IL-2 promoter-CAT construct only in the presence of Oct2 and it was suggested that Oct- 2 in T-cells circumvents the need for the addition of mitogen for the induction of IL-2 [40]. These results demonstrate the need to investigate the action of kinases (and phosphatases) in the context of accessory proteins normally present in the cell.

In addition to the regulation of DNA-binding activity by cellular kinases, our results suggest that octamer DNA-binding activity is also regulated by nuclear phosphatases. Okadaic acid 
inhibits Oct-1 and Oct-2 binding, implicating PP-2A [28] as a regulator of octamer DNA binding to the $\mathrm{H} 2 \mathrm{~B}$ promoter. Okadaic acid activates p34 $4^{c d c 2}$ [42], so the possibility of an indirect effect cannot be excluded. In contrast with our observations on the $\mathrm{H} 2 \mathrm{~B}$ promoter, octamer binding to the TAATGARAT motif is sensitive to a general phosphatase inhibitor cocktail but not to okadaic acid, suggesting regulation by phosphatases other than PP-1A or PP-2A. PP-2B is a candidate for such a phosphatase because calcineurin/PP-2B has been shown to augment Oct-1-dependent transcription of the IL2 gene [18]. Furthermore we have shown that PKA enhances Oct-1 and Oct-2 DNA binding to the octamer motif in the presence of active phosphatases, but attenuates binding when phosphatase activity is inhibited. The mechanisms involved remain to be determined. As discussed above for PKC, these effects of PKA might not be direct and could be via cofactors or other kinases/phosphatases in the nuclear extract. Nevertheless, our results indicate that the balance of phosphatase and kinase activities within the nucleus represents an extremely sensitive mechanism whereby the interaction of both Oct-1 and Oct- 2 with different DNA binding sites could be regulated.

Not all post-translational modifications alter Oct-1 and Oct-2 DNA binding in a sequence-specific manner. Rigoni et al. [43] have shown that oxidation of cysteine residues in the POU domain of Oct-2 inhibit binding to the octamer binding site in the $\mathrm{IgH}$ promoter. When we extended these observations to include the TAATGARAT and overlapping binding sites, we found that oxidation completely abolished binding of both Oct-1 and Oct2 to octamer, TAATGARAT and overlapping binding sites, whereas reduction with dithiothreitol had no effect on DNAbinding activity (results not shown). Thus oxidation/reduction might represent a general mechanism whereby octamer-mediated transcription can be switched on or off, and phosphorylation might represent a mechanism whereby octamer-mediated transcription of specific gene(s) is regulated.

Phosphorylation could represent a specific mechanism whereby Oct- 1 and Oct-2 binding to low-affinity DNA binding sites is regulated independently of high-affinity binding sites. Such a mechanism has been described for other transcription factors, notably p53 [21] and the POU domain transcription factor, Pit1 [22,23]. Phosphorylation of Pit-1 by PKA or PKC enhances Pit-1 binding to TSH- $\beta$ elements $3-8$-fold but decreases DNA binding to elements within the prolactin and growth hormone genes [22,23]. Similarly it has recently been shown that phosphorylation of p53 by two kinases (cyclin B-cdc 2 and cyclin A-cdk2) causes distinct conformational changes in p53 and that this differentially regulates the ability of p53 to bind to DNA binding sites [21]. Our results also suggest that different kinases (PKA, PKC and CK-II) can differentially regulate the binding of both Oct-1 and Oct-2 to three different DNA binding sites. The mechanisms involved and their physiological relevance have yet to be elucidated, but clearly represent a mechanism whereby certain genes could be transcribed at high levels at all times whereas others could be transcribed in response to extracellular stimuli or in a cell-cycle-dependent manner.

We thank R.-H. Charollais for comments on the manuscript and helpful discussions. This project was supported by grants from the Leukaemia Research Fund and the Kay Kendall Leukaemia Fund.

\section{REFERENCES}

1 Verrijzer, C. P. and van der Vliet, P. C. (1993) Biochim. Biophys. Acta 1173, 1-21

2 Sturm, R. A. and Herr, W. (1988) Nature (London) 336, 601-604

3 Clerc, R. G., Cocoran, L. M., LeBowitz, J. H., Baltimore, D. and Sharp, P. A. (1988) Genes Dev. 2, 1570-1581

4 Ko, H. S., Fast, P., McBride, W. and Staudt, L. M. (1988) Cell 55, 135-144

5 Scheidereit, C., Cromlish, J. A., Gerster, T., Kawakami, K., Balmaceda, C. G., Currie, R. A. and Roeder, R. G. (1988) Nature (London) 336, 551-557

6 Hatzopoulos, A., Stoyoka, A. S., Erselins, J. R., Goulding, M., Neuman, T. and Gruss, P. (1990) Development 109, 349-362

7 He, X., Treacy, M. N., Simmons, D. M., Ingraham, H. A., Swanson, L. S. and Rosenfeld, M. G. (1989) Nature (London) 340, 35-42

8 Singh, H., Sen, R., Baltimore, D. and Sharp, P. A. (1986) Nature (London) 319 154-158

9 Staudt, L. M., Clerc, R. G., Singh, H., LeBowitz, J. H., Sharp, P. A. and Baltimore, D. (1988) Science 241, 577-580

10 Sive, H. L. and Roeder, R. G. (1986) Proc. Natl. Acad. Sci. U.S.A. 83, 6382-6386

11 Fletcher, C., Heintz, N. and Roeder, R. G. (1987) Cell 51, 773-781

12 Cocoran, L. M., Karvelas, M., Nossal, G. J., Ye, Z. S., Jacks, T. and Baltimore, D. (1993) Genes Dev. 7, 570-582

13 Corcoran, L. M. and Karvelas, M. (1994) Immunity 1, 635-645

14 Wheatley, S. C., Kemp, L. M., Wood, J. N. and Latchman, D. S. (1990) Exp. Cell Res. 190, 243-246

15 Hunter, T. and Karin, M. (1992) Cell 70, 375-387

16 Karin, M. (1994) Curr. Opin. Cell Biol. 6, 415-424

17 Segil, N., Roberts, S. B. and Heintz, N. (1991) Science 254, 1814-1816

18 Clipstone, N. A. and Crabtree, G. R. (1992) Nature (London) 357, 695-697

19 Roberts, S. B., Segil, N. and Heintz, N. (1991) Science 253, 1022-1026

20 Tanaka, M. and Herr, W. (1990) Cell 60, 375-386

21 Wang, Y. and Prives, C. (1995) Nature (London) 376, 88-91

22 Kapiloff, M. S., Farash, Y., Wegner, M. and Rosenfeld, M. G. (1991) Science 253 786-789

23 Steinfelder, H. J., Rodovick, S. and Wondisfold, F. E. (1992) Proc. Natl. Acad. Sci. U.S.A. 89, 5942-5942

24 Dent, C. L., Lillycrop, K. A., Estridge, J. K., Thomas N. S. B. and Latchman, D. S. (1991) Mol. Cell. Biol. 11, 3925-3930

25 Dent, C. L. and Latchman, D. S. (1991). Biochem. J. 277, 541-545

26 Schreiber, E., Matthias, P., Muller, M. M. and Schaffner, W. (1989) Nucleic Acid Res. 17, 6419

27 Dent, C. L., Lillycrop, K. A., Bybee, A., Latchman, D. S. and Thomas, N. S. B. (1991) J. Biol. Chem. 266, 20888-20892

28 Hardie, D. G. (ed.) Protein Phosphorylation, A Practical Approach. IRL Press/Oxford University Press, Oxford

29 Reference deleted

30 Verrijzer, C. P., Alkema, M. J., van Weperen, W. W., van Leeuwen, H. C., Strating, J. J. and van der Vliet, P. C. (1992) EMBO J. 11, 4993-5003

31 Klemm, J. D., Rould, M. A., Aurora, R., Herr, W. and Pabo, C. 0. (1994) Cell 77, 21-32

32 Dekker, N., Cox, M., Boelens, R., Verrijzer, C. P., van der Vliet, P. C. and Kaptein, R. (1993) Nature (London) 362, 852-855

33 Meisner, H. and Chech, M. P. (1991) Curr. Opin. Cell Biol. 3, 474-483

34 Lai, J. S., Cleary, M. A. and Herr, W. (1992) Genes Dev. 6, 2058-2065

35 Gerster, T. and Roeder, R. G. (1988) Proc. Natl. Acad. Sci. U.S.A. 85, 6347-635

36 Frantz, B., Nordby, E. C., Bren, G., Steffan, N., Paya, C. V., Kincaid, R. L., Tocci, M. J., O'Keefe, S. J. O. and Neill, A. O. (1994) EMBO J. 13, 861-870

37 Bhargava, A. K., Li, Z. and Weissman, S. M. (1993) Proc. Natl. Acad. Sci. U.S.A. 90, 10260-10264

38 Granelli-Piperno, A. and Nolan, P. (1991) J. Immunol. 147, 2734-2739

39 Gruters, R. A., Otto, S. A., Al, B. J. M., Verhoeven, A. J., Verweij, C.L, Van Lier, R. A. W. and Miedema, F. (1991) Eur. J. Immunol. 21, 167-172

40 Kamps, M. P., Corcoran, L., LeBowitz, J. H. and Baltimore, D. (1990) Mol. Cell. Biol. 10, $5464-5472$

41 Marti, A., Jehn, B., Costello, E., Keon, N., Ke, G., Martin, F. and Jaggi, R. (1994) Oncogene 9, 1213-1223

42 Yamahita, K., Yasuda, H., Pines, J., Yasumoto, K., Nishitani, H., Ohsubo, M., Hunter, T., Sugimura, T. and Nishimoto, T. (1990) EMBO J. 9, 4331-4338

43 Rigoni, P., Xu, L., Harshman, K., Schaffner, W. and Arnosti, D. N. (1993) Biochim. Biophys. Acta 1173, 141-146

Received 1 September 1995/1 December 1995; accepted 22 December 1995 